\title{
Atmospheric influence on the deuterium excess signal in polar firn: implications for ice-core interpretation
}

\author{
Elisabeth SCHLOSSER, ${ }^{1}$ Hans OERTER, ${ }^{2}$ Valerie MASSON-DELMOTTE, ${ }^{3}$ \\ Carleen REIJMER ${ }^{4}$ \\ ${ }^{1}$ Institute of Meteorology and Geophysics, University of Innsbruck, Innrain 52, A-6020 Innsbruck, Austria \\ E-mail: elisabeth.schlosser@uibk.ac.at \\ ${ }^{2}$ Alfred-Wegener Institute for Polar and Marine Research, Postfach 120161, D-27515 Bremerhaven, Germany \\ ${ }^{3}$ Laboratoire des Sciences du Climate et de l'Environnement, Laboratoire mixte CEA-CNRS-CE Saclay, \\ 91191 Gif-sur-YvetteCedex, France \\ ${ }^{4}$ Institute for Marine and Atmospheric Research, University of Utrecht, Princetonplein 5, \\ NL-3584 CC Utrecht, The Netherlands
}

\begin{abstract}
The seasonal deuterium excess signal of fresh snow samples from Neumayer station, coastal Dronning Maud Land, Antarctica, was studied to investigate the relationship between deuterium excess and precipitation origin. An isotope model was combined with a trajectory model to determine the relative influence of different moisture sources on the mean annual course of the deuterium excess, focusing on the phase lag between $\delta^{18} \mathrm{O}$ and excess $\mathrm{d}$. Whereas the annual course of $\delta^{18} \mathrm{O}$ always shows an austral summer maximum, which clearly depends on local temperature and the annual course of moisture source-area parameters, the deuterium excess of the fresh snow samples shows maximum values already in spring. There can be many different reasons for the time lag between $\delta^{18} \mathrm{O}$ and deuterium excess in an ice core, including post-depositional processes and changes in the moisture source of precipitation. The use of fresh snow samples enabled us to exclude post-depositional processes and study solely the influence of precipitation origin. Changes in the moisture source connected to systematic changes in the general atmospheric circulation can have a strong influence on the phase lag between deuterium excess and $\delta^{18} \mathrm{O}$, which has to be taken into account for climatic interpretation of stable-isotope profiles from ice cores.
\end{abstract}

\section{INTRODUCTION}

In order to assess the climatic change observed currently and possible future changes in climate, it is necessary to fully understand climatic changes in the past. During recent decades considerable progress in paleoclimatology has been made, especially due to the investigation of physical and chemical properties of ice cores from deep drillings in Greenland and Antarctica (e.g. EPICA Community Members, 2004, 2006; NorthGRIP Members, 2004). For temperature reconstruction, the measurement of stable-isotope ratios of water is crucial, since a linear relationship was found between the stable oxygen-isotope ratio of the snow/ice, $\delta^{18} \mathrm{O}$ (and/or the deuterium $\mathrm{D}\left({ }^{2} \mathrm{H}\right)$, which is at first order linearly related to the ${ }^{18} \mathrm{O}$ content), and the mean annual air temperature at the deposition site (Dansgaard, 1964). The $\delta$ notation is used for both ${ }^{18} \mathrm{O}$ and $\mathrm{D}$ to express the isotopic ratio relative to Standard Mean Ocean Water (SMOW). The stable-isotope ratios depend on fractionation processes, which occur during most phase changes of water during its atmospheric cycle due to the different saturation vapour pressure and molecular diffusivities of the heavier and lighter water molecules, respectively. For calculation of the fractionation coefficients it is assumed that this fractionation occurs in thermodynamical equilibrium, which is fulfilled only in a very thin layer at the water-air interface. In addition to the so-called 'equilibrium fractionation', a 'kinetic' effect occurs during molecular diffusion through the layer just above the water. The diffusion constants in air are inversely proportional to mass, thus the lighter and heavier isotopes again behave differently (Jouzel and others, 1997). Recently, increasing attention has been given to the deuterium excess $d=\delta \mathrm{D}-8 \delta^{18} \mathrm{O}$, which reflects the slightly different behaviour of hydrogen and oxygen isotopes during kinetic fractionation of $\mathrm{H}_{2} \mathrm{O}$. The equilibrium effect is eight to ten times higher for deuterium than for ${ }^{18} \mathrm{O}$, whereas the kinetic effects are of the same order. Therefore, the relative contribution of kinetic fractionation is larger for ${ }^{18} \mathrm{O}$ than for deuterium D. It was found that the deuterium excess $d$ mainly depends on evaporation kinetics (properties of the oceanic moisture source, namely the sea surface temperature (SST), which influences the saturation vapour pressure, the relative humidity, since it controls the vapour diffusion, and wind speed, which controls the turbulent vapour transport at higher levels) and also the kinetics of ice crystal formation in clouds (Jouzel and Merlivat, 1984). Thus the excess yields integrated information about precipitation origin.

As a result, the isotope ratio of polar precipitation is influenced by many other factors apart from air temperature (Steig and others 1994; Jouzel and others, 1997, 2003; Noone and Simmonds, 1998; Noone and others, 1999; Schlosser, 1999; Werner and others, 2000; Schlosser and Oerter, 2002). Of special interest here is the origin of precipitation (Delaygue and others, 1999; Reijmer and Van den Broeke, 2001; Schlosser and others, 2004). Changes in the moisture source can lead to considerable changes in the isotope ratio, since this means a change in the whole precipitation history, from the first evaporation from the ocean along different transport paths to the final deposition at the drilling site, therefore also in the history of fractionation processes. Thus, to obtain a correct quantification of past temperature changes from isotopic records measured 
on ice cores, we need to know the moisture sources for different areas and climate periods, respectively. In the frame of the European Project for Ice Coring in Antarctica (EPICA) the second deep drilling was finished in the austral summer 2005/06 (EPICA Community Members, 2006), reaching bedrock at $2774 \mathrm{~m}$ depth. The location for this so-called EPICA-Dronning Maud Land (EDML) core was chosen in the Atlantic sector of Antarctica $\left(75^{\circ} \mathrm{S}, 0^{\circ} \mathrm{E}\right)$ to investigate the influence of the Atlantic Ocean on the climate of Antarctica. Whereas the first EPICA core at Dome C (EDC) (EPICA Community Members, 2004), with a mean accumulation rate of $28 \mathrm{~mm}$ w.e. $\mathrm{a}^{-1}$ (Parrenin and others, 2007), aimed at obtaining ice as old as possible, accumulation at the EDML drilling site is almost three times as high as at Dome $\mathrm{C}$ $\left(64 \mathrm{~mm}\right.$ w.e. $\left.\mathrm{a}^{-1}\right)$ and thus the core has a much higher temporal resolution than the EDC core. The EDML core is of special interest with regard to obtaining information about the meteorological conditions related to the stable-isotope ratios and the influence of moisture origin changes on the isotope ratios in this area. The EDML core is much more influenced by synoptic activity of the circumpolar trough than are the EDC or Vostok cores. Precipitation is not mainly clear-sky precipitation, but several times per year relatively strong precipitation events occur that are connected to cyclone activity (Birnbaum and Brauner, 2006). The EDML drilling site and the area of Neumayer station are partly affected by the same systems.

Our study aims at a better understanding of the relationship between stable isotopes in snow and ice and the atmospheric conditions prevailing during the corresponding precipitation events. In particular, we are interested in the influence of precipitation origin on the deuterium excess. To achieve this goal we combine an isotope model with a trajectory model. The use of fresh snow samples enables us to exclude post-depositional processes, which also influence the isotopic composition of the snow. Thus we are able to study solely the influence of precipitation origin on the deuterium excess, using both modelled and observed isotope data.

Special emphasis is placed on the phase difference between deuterium excess and $\delta^{18} \mathrm{O}$, which is poorly understood to date. Delmotte and others (2000) report a time lag between ${ }^{18} \mathrm{O}$ and deuterium excess of 4 months, with a maximum of excess in late autumn (May, June). For Greenland, Johnsen and others (1989) and Hoffmann and others (1998b) found $d$ and $\delta^{18} \mathrm{O}$ to be in anti-phase for low altitudes, whereas at higher altitudes $d$ lagged $\delta^{18} \mathrm{O}$ by about 3 months. At the South Pole, a lag of $d$ of about 5 months was reported by Ciais and others (1995). Oerter and others (2004) found in a snow pit dug close to the EDML drilling site that the phase lag between $d$ and $\delta^{18} \mathrm{O}$ was depthdependent. In the topmost layers ${ }^{18} \mathrm{O}$ and $d$ were in antiphase and got in phase within the first $2 \mathrm{~m}$. These results were explained by post-depositional processes, namely diffusion during metamorphism of the snow cover (Johnsen and Robin, 1983). Therefore, obviously there are large regional and temporal differences in this phase lag, which cannot be explained uniformly.

\section{PREVIOUS STUDIES OF PRECIPITATION ORIGIN}

Different authors have tried to investigate the origin of precipitation using various modelling approaches. There are principally two different types of model for calculation of stable isotopes: (1) theoretical distillation Rayleigh-type models (here called RMs) (Merlivat and Jouzel, 1979; Jouzel and Merlivat, 1984) that consider only an isolated air parcel without atmospheric dynamics, sometimes extended to a zonal approach (e.g. Fisher, 1990); and (2) atmospheric general circulation models (GCMs), equipped with water cycles for each water isotope, which model three-dimensionally the dynamics of the atmosphere (with a relatively coarse resolution), but which do not resolve realistic 'real-time' synoptic conditions. Additionally, trajectory models are used to determine the origin of air masses by calculating backwards trajectories.

Ciais and others (1995) used an improved version of the original RM, the so-called mixed-cloud isotope model (MCIM) (Ciais and Jouzel, 1994), to calculate the deuterium excess of surface snow from two different Antarctic sites in order to determine the origin of present-day Antarctic precipitation. Although they use the phase difference between deuterium and deuterium excess as an additional independent variable, the lack of any atmospheric dynamics in the model might have influenced their results: a subtropical $\left(20-40^{\circ} \mathrm{S}\right)$ moisture source for both the coastal and the inland site. Delmotte and others (2000) investigated the origin of precipitation for Law Dome, coastal eastern Antarctica, using deuterium excess data from two shallow ice cores and both the MCIM and a GCM. They showed that the seasonal cycle of deuterium excess depends on a combination of the effects of the Southern Ocean seasonal temperature cycle and seasonal moisture origin changes.

Reijmer and Van den Broeke (2001) obtained different results using a three-dimensional trajectory model: for Dronning Maud Land (DML) they found the main moisture source between $40^{\circ} \mathrm{S}$ and $60^{\circ} \mathrm{S}$. Reijmer and others (2002) used the same model to investigate moisture sources for five different deep drilling sites in Antarctica. They came to the conclusion that the ocean closest to the site contributes the most moisture. Thirty percent of the annual precipitation came from the latitude band $50-60^{\circ} \mathrm{S}$, which is in better agreement with the experience of practical Antarctic meteorologists and forecasters than a subtropical moisture source (e.g. Pfaff, 1993). Using the same trajectory model, Schlosser and others (2004) studied the origin of precipitation for Neumayer station, at the coast of western DML. Different trajectory classes related to the synoptic weather pattern were defined and it could be shown that the quality of the $\delta^{18} \mathrm{O}$-temperature relationship depended strongly on the trajectory class, thus on the origin and transport mechanism of precipitation.

Delaygue and others $(1999,2000)$ investigated the climatic stability of the origin of Antarctic precipitation using the GCM of NASA Goddard Institute of Space Studies (GISS Model). Using CLIMAP glacial SST, they found no significant difference in the moisture source between the Last Glacial Maximum (LGM) and today, except a slightly enhanced contribution of moisture from lower latitudes to Antarctic precipitation at the LGM.

One problem with the RMs is the lack of data for an independent calibration of the model. Usually the models are tuned so as to make them reproduce the data measured in an ice core or along a traverse, but there are no additional data available to validate the calibration.

A second restriction in the use of these simple distillation models is that they assume too simple dynamic conditions in the atmosphere, namely a smooth lifting and cooling of the 
air masses due to the orography of the Antarctic continent, without taking into account the more complex atmospheric dynamics especially in the circumpolar low-pressure belt. In this study we aimed to improve the isotope modelling by combining the MCIM with a trajectory model. Helsen and others (2007) conducted a similar study using the MCIM and snow-pit data from the vicinity of Kohnen station, DML, covering a time period of 4-6 years. However, they did not use the MCIM independently, but combined it with GCM data by readjusting the isotope values for water vapour along the trajectory using the GCM results.

\section{DATA}

At the German Antarctic wintering base, Neumayer station on Ekströmisen, an extensive glaciometeorological programme has been carried out since 1981. This includes stable-isotope measurements $\left(\delta^{18} \mathrm{O}\right.$ and $\delta \mathrm{D}$, thus also the deuterium excess, $d$ ) from snow pits, shallow firn cores and fresh snow samples. The latter are taken after each major snowfall event, preferably after an event with no, or only little, wind. But most snowfall events at Antarctic coastal stations are accompanied by at least moderate winds, so there is always a possibility of error due to mixing of older snow into the precipitation by snowdrifting. The data density varies largely from year to year, depending on the assessment by the corresponding wintering scientists of the strength of the wind influence. The Neumayer dataset is unique in Antarctica: it is the only long-term stable-isotope time series of snow samples that can be unambiguously related to certain precipitation events with well-known synoptic conditions, which enables us to study the deuterium excess based on single precipitation events. Apart from the study by Fujita and Abe (2006), who investigated the stable-isotope ratios of daily precipitation samples at Dome F over 1 year (2003), all other studies on the seasonal cycles of stable isotopes have been conducted on snow pits and ice cores, which raises problems of diffusion if accumulation rates are comparable to, or smaller than, the diffusion length. (The only exception here is Law Dome due to its extremely high accumulation rates (Masson-Delmotte and others, 2003)).

The samples were stored under frozen conditions at Neumayer station and in the following summer shipped to the Alfred Wegener Institute (AWI), Bremerhaven, Germany. The isotope analysis (both $\delta^{18} \mathrm{O}$ and $\delta \mathrm{D}$ ) was carried out for the years 1981-99 at the National Research Centre for Environment and Health (GSF) (Schlosser and others, 2004), Neuherberg, Germany, and after 1999 at AWI. The accuracy of the isotope measurements is $0.1 \%$ for the $\delta^{18} \mathrm{O}$ and $1.0 \%$ for the deuterium, resulting in a quadratic error of $1.3 \%$ for deuterium excess. In this study we used a set of 340 fresh snow samples taken between 1981 and 2000.

Additionally, a full meteorological dataset including upper-air soundings is available for Neumayer station (König-Langlo and Marx, 1997).

\section{THE TRAJECTORY MODEL}

Here we used the trajectory model that was developed by the Royal Netherlands Meteorological Institute (KNMI) (Scheele and others, 1996; Reijmer and Van den Broeke, 2001; Stohl and others, 2001; Reijmer and others, 2002) to calculate air-parcel backward trajectories.
The three-dimensional displacement of an air parcel during a time-step $\Delta \mathrm{t}$ is calculated using an iterative scheme:

$$
X_{n+1}=X_{0}+\Delta t / 2\left[v\left(X_{0}, t\right)+v\left(X_{n}, t+\Delta t\right)\right],
$$

where $\Delta t$ is the iteration time-step, $X_{0}$ is the position vector of the parcel at time $t, X_{n}$ is the $n$th iterative approximation of the position vector at time $t+\Delta t$, and $v(X, t)$ is the wind vector at position $X$ and time $t$. An iteration step of $-10 \mathrm{~min}$ was chosen. The iteration stops when the horizontal distance between $X_{n}$ and $X_{n=1}$ is $<300 \mathrm{~m}$ and the relative vertical pressure difference, defined as $\left(P_{n+1}-P\right) / P_{n+1}$, is $<0.0001$.

The model is able to calculate isentropic, isobaric or fully three-dimensional trajectories. In this case we used the fully three-dimensional trajectories, because they best simulate atmospheric transport processes (Stohl and others, 1995; Kottmeyer and Fay, 1998). As input for the trajectory model, analyses from the European Centre for Medium-Range Weather Forecasts (ECMWF) numerical weather-forecast model were used. For the period 1981-93, data from the 15 year re-analysis (ERA15) were used, and for the period 1994-2000 data from the 40 year re-analysis (ERA40) were used. Possible inconsistencies due to the change of reanalysis are small compared with the main uncertainties in the trajectory calculation mentioned later. The choice of data depended on their availability during calculation of the trajectories. The resolution of the input data was kept constant at $1.5^{\circ}$ horizontally and 6 hours in time. Vertically, resolution changes from 31 levels for the ERA15 period to 60 levels for the ERA40 period. The data had to be interpolated in time and space. The spatial interpolation is bilinear in the horizontal, and linear with $\log$ (pressure) in the vertical. The time interpolation is quadratic. For each day with fresh snow samples available, a 5 day backward trajectory was calculated, starting at $1200 \mathrm{~h}$ GMT on the last precipitation day.

The main reasons for uncertainties in the calculated trajectories are errors in the wind fields, particularly the vertical wind component, and in the interpolation of the data. Numerical truncation errors seem to be of minor importance (Stohl and others, 2001). However, especially in areas with low data density, as in and around Antarctica, trajectory errors can be large. After 5 days, the error can be in the order of $1000 \mathrm{~km}$ (Kahl and others, 1989; Stohl and others, 2001). Average errors of approximately $20 \%$ of the travel distance may be considered typical (Stohl and others, 2001). The calculated trajectories were also cross-checked using ECMWF surface pressure maps and $500 \mathrm{hPa}$ geopotential height fields. Nevertheless, it means a simplification to define the starting point of the trajectory (the end point of the backward trajectory) as 'moisture origin', since from the trajectory alone it is not possible to determine where the main moisture source lies and there is also entrainment of additional (moist) air masses along the trajectory. The possible moisture origin was determined using the trajectory calculation combined with synoptic experience and ECMWF analyses, which means that it is not always the end of the 5 day backwards trajectory.

In spite of the uncertainties described earlier, it was usually possible to determine clearly whether the moisture sources are located in the South Polar Ocean or at lower latitudes, and whether the transport took place over ice (sea ice, ice shelf or inland ice) or across the open sea. Thus, if used cautiously, the trajectories are a useful tool for investigating the transport of air masses to the deposition site of precipitation. 


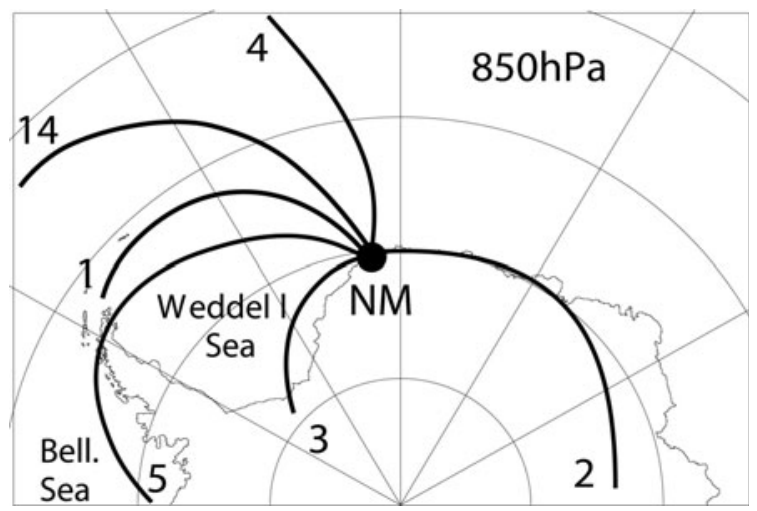

Fig. 1. Definition of trajectory classes for arrival level $850 \mathrm{hPa}$ at Neumayer station: 1: Weddell Sea, 2: continental east, 3: southern origin, 4: low latitudes, 5: Bellingshausen Sea (Southern Ocean), 14: north of Weddell Sea (between classes 1 and 4).

\section{THE MIXED-CLOUD ISOTOPE MODEL}

A hierarchy of isotope models has been developed, reaching from dynamically simple Rayleigh-type distillation models (Dansgaard, 1964; Merlivat and Jouzel, 1979; Jouzel and Merlivat, 1984; Fisher, 1990; Ciais and Jouzel, 1994) to atmospheric GCMs (Hoffmann and others, 1998a, b; Werner and others, 2000). For our investigation, we used the MCIM developed by Ciais and Jouzel (1994). It is a distillation model, which calculates the isotope ratios of water, water vapour and solid ice during precipitation formation. After the first evaporation from the ocean, the air is lifted and cooled continuously. When the dew point is reached, the condensation process starts. The isotope ratio of the initial water vapour can be calculated by the model, using meteorological data of the assumed oceanic source area (wind speed, relative humidity and SST), assuming a closed system and a local isotopic balance between precipitation and evaporation (the so-called closure equation; Merlivat and Jouzel, 1979), or can be taken from GCMs. At each step, a certain (adjustable) fraction of the condensate is removed from the cloud as precipitation. The model allows the coexistence of solid ice and liquid water in the cloud, which means that the environment is undersaturated with respect to the liquid phase while it is supersaturated with respect to the solid phase. Thus evaporation from liquid droplets and sublimation onto ice crystals will take place, the so-called
Bergeron-Findeisen process (Mason, 1971). Ice formation can therefore be due to two different phase transitions: (i) freezing of supercooled droplets, which is not accompanied by isotopic fractionation; or (ii) direct deposition of vapour onto existing crystals, which does change the isotope ratio, especially due to kinetic fractionation, since the droplets are not in isotopic equilibrium with the vapour. The limits of the temperature range, for which ice and liquid water can coexist, are adjustable. For each step, the isotopic composition of the different airborne phases and the precipitation is calculated.

\section{TRAJECTORY STUDY}

In this study, we directly combined the MCIM (Ciais and Jouzel, 1994) with the trajectory model mentioned earlier (Reijmer and Van den Broeke, 2001), in order to include information about the atmospheric dynamics in the isotope model. Isotope fractionation was calculated along different trajectories typical for synoptic conditions at Neumayer station. The trajectories were calculated as 5 day backward trajectories. Six different trajectory classes were defined, which are shown in Figure 1 for arrival level $850 \mathrm{hPa}$. (For details about the trajectory study see Schlosser and others (2004). The trajectories fell so strikingly into only a few different classes that no mathematical algorithm was used to define them, they were assigned to each category manually. No overlapping between different classes occurred.) The arrival level $850 \mathrm{hPa}$ was chosen because, at Neumayer station, this is supposed to be on average close to the condensation level, thus most important for precipitation. The corresponding frequency distribution is found in Table 1. The most frequent trajectory class is class 1 , which means an origin close to the Antarctic Peninsula and transport above the Weddell Sea or its northern boundary. Next is class 2, corresponding to a trajectory from the east. Class 3, transport path from the south, has a frequency of only $13 \%$, but can have very strong isotope signals, as will be shown later. Class 4 occurs in only $10 \%$ of all cases, but can bring a relatively high amount of precipitation, since it is connected to advection of warm and thus moist air from lower latitudes. Class 5 means a source area somewhere in the Bellingshausen Sea and its surroundings. The Bellingshausen Sea is one of the areas of the Southern Ocean that has multi-year sea ice, nevertheless it means a moisture source in the Southern Ocean, close to the coast of the continent. Finally,

Table 1. Longitude and latitude range for source area corresponding to the different trajectory classes, mean deuterium excess $d$ of surface snow samples and standard deviation for different trajectory classes (arrival level $850 \mathrm{hPa}$ ). $n$ is the number of cases (samples) for the corresponding trajectory class. (The sum for all classes is smaller than the total number of samples, since trajectories that did not belong unambiguously to a certain class, and trajectories with kinks, which were not trustworthy dynamically, were excluded.) The last column gives the frequency distribution of the trajectory classes. Bold and italic numbers refer to maximuim and minimum mean $d$, respectively

\begin{tabular}{|c|c|c|c|c|c|c|}
\hline Trajectory class & Latitude range & Longitude range & $\begin{array}{c}\text { Mean } d \\
\% o\end{array}$ & $\begin{array}{c}\text { Std dev. } \\
\% o\end{array}$ & $n$ & $\%$ \\
\hline 1 (Weddell Sea) & $62-65^{\circ} \mathrm{S}$ & $30-0^{\circ} \mathrm{W}$ & 8.94 & 5.28 & 80 & 32 \\
\hline 2 (continental east) & $65-70^{\circ} \mathrm{S}$ & $45-30^{\circ} \mathrm{E}$ & 8.89 & 6.17 & 73 & 29 \\
\hline 3 (continental south) & $73-76^{\circ} \mathrm{S}$ & $45-30^{\circ} \mathrm{W}$ & 10.91 & 10.31 & 34 & 13 \\
\hline 4 (low latitude) & $45-55^{\circ} \mathrm{S}$ & $30-10^{\circ} \mathrm{W}$ & 6.15 & 4.40 & 26 & 10 \\
\hline 5 (Bellingshausen Sea) & $68-72^{\circ} \mathrm{S}$ & $100-80^{\circ} \mathrm{W}$ & 7.80 & 3.43 & 18 & 7 \\
\hline 14 (between 1 and 4) & $58-62^{\circ} \mathrm{S}$ & $60-40^{\circ} \mathrm{W}$ & 6.70 & 5.66 & 24 & 9 \\
\hline
\end{tabular}


class 14 lies between class 1 and class 4 , and thus is not a really low-latitude moisture source, but not from the Weddell Sea either.

\section{MEASURED DEUTERIUM EXCESS FOR DIFFERENT MOISTURE ORIGINS}

Table 1 shows the mean deuterium excess of the surface snow samples for each trajectory class. Although the average was calculated from all available data for each class, without differentiating for different seasons, both the deuterium excess and the $\delta^{18} \mathrm{O}$ show clear systematic differences in the isotope values for different trajectory classes, but due to the high variability of the data (particularly the deuterium excess) the results are not always statistically significant. However, the differences in isotope ratios for the different moisture origins can be explained physically in a plausible way. Maximum values for the excess are found for class 3 , which means air advection from cold areas in the interior of the continent. After the first evaporation in an unknown ocean area, this air mass has had a long transport path with orographic lifting above the continent, followed by a return to the coast (Neumayer) where dynamic atmospheric processes lead to precipitation. This means that this air has undergone many more condensation processes than for class 4 or 14 , where the air has come directly from some oceanic source with no orographic lifting on the way to the coastal Neumayer station. Correspondingly, the lowest values of $d$ are found for classes 4 and 14 (Table 1) (see also Schlosser and others, 2004).

The measurements at Neumayer are being continued and hopefully these will resolve the issue of whether the lack of statistically different results between most trajectory classes is due to undersampling or to other physical reasons, which need further investigation. With a larger amount of data the study could be done separately for different seasons, which thus far did not show any different or clearer results than the calculation with the data from the whole year.

\section{ISOTOPE MODELLING WITH THE MIXED-CLOUD ISOTOPE MODEL}

The conditions at the moisture sources derived by the trajectory study are the input parameters for the MCIM. The areas we defined as 'moisture sources' are shown in Table 1. The area of the moisture sources is not always the same, it depends on the spreading of the trajectory starting points.

To calculate the initial isotope ratio of the first water vapour after evaporation from the oceanic moisture source we used both the closure equation and climatological values from a GCM (ECHAM4; Hoffmann and others, 1998a). Starting with the first evaporation at the oceanic moisture source, the MCIM then calculates the isotope ratios for the whole transport path using different fractionation coefficients for equilibrium fractionation and kinetic fractionation, and for ${ }^{18} \mathrm{O}$ and $\mathrm{D}$, respectively. The amount of precipitation that is removed from the cloud after condensation is one of the most important tuning parameters. The model also reacts highly sensitively on the initial values of either source meteorological conditions or isotope ratios of the first water vapour. Since the uncertainties for these variables are fairly high, it was not possible to tune the model unambiguously in terms of absolute values of $\delta^{18} \mathrm{O}, \mathrm{D}$ and $\mathrm{d}$. However, the model was able to reproduce the correct annual cycles of
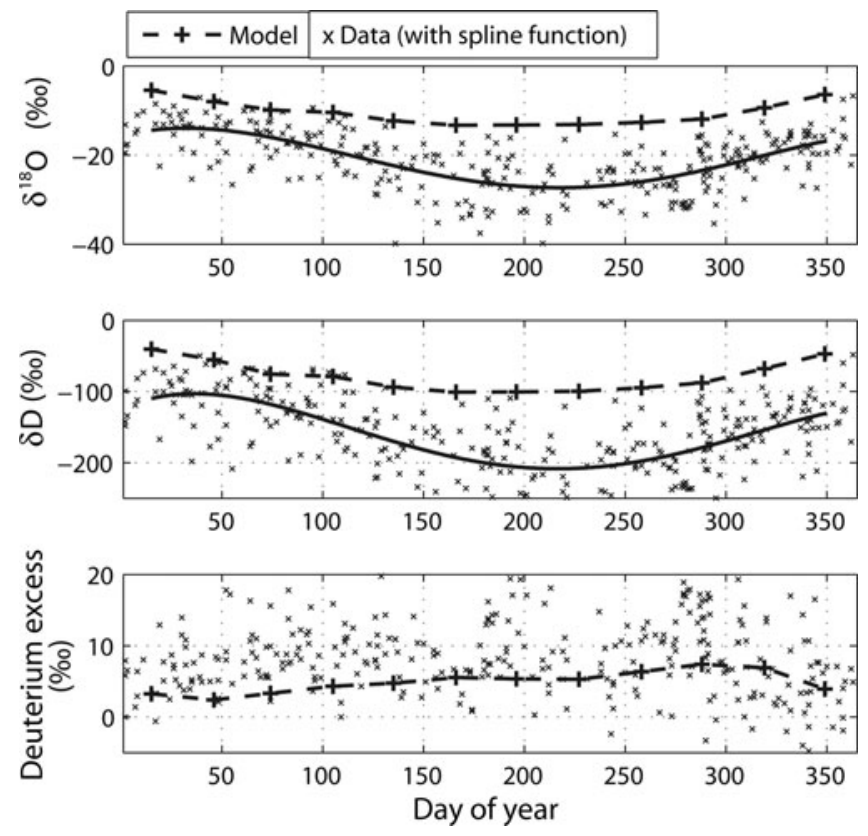

Fig. 2. Measured (based on single precipitation events) and modelled (based on monthly averages) mean annual cycle of $\delta^{18} \mathrm{O}, \delta \mathrm{D}$ and $d$. The data were measured in fresh snow samples taken immediately after snowfall events during the years 1981-2000. Data curves are fifth and fourth degree polynomials and cubic splines for $\mathrm{O}^{18}$, deuterium and deuterium excess, respectively (see explanation in the text).

these isotope values. Figure 2 shows the modelled annual course of $\delta^{18} \mathrm{O}, \mathrm{D}$ and $\mathrm{d}$ of the surface snow samples as well as the corresponding data curves. (We deliberately refrained from giving error bars here, because the error in both modelled and observed values cannot be quantified in a reasonable way, as can be easily understood from the discussion of the error possibilities.) The data curves in this figure are fourth and fifth degree polynomials through the given data for deuterium and ${ }^{18} \mathrm{O}$, respectively. Since the data density is not the same each year, and the curves are plots of all measured data put into one 'synthetic' year (the $x$ axis is day of the year), December and January values are not necessarily from two consecutive years, and sometimes only a few measurements are available anyway. Thus the end-of-December and beginning-of-January values do not necessarily have to be the same. Rather than calculating an artificial mean annual course, the polynomial functions were used. The annual cycle of the deuterium excess depends on the trajectory class (see later), thus it cannot be seen in a plot of all data, so no spline is given here.

The model curves were first calculated individually for each trajectory class (using monthly means of the corresponding source-area conditions) and then weighted by the frequency distribution of the trajectories shown in Table 1. In this case, the ECHAM4 values were used as initial values for the water vapour. Using the closure equation only leads to a parallel (downward) shift of the curves. Here we chose the combination of tuning parameters that gave the best agreement between model and data for the deuterium excess. It was not possible to choose a combination of tuning parameters that made sense physically and yielded good agreement between model and data for all three isotope values $\left(d, \mathrm{D}\right.$ and $\left.\delta^{18} \mathrm{O}\right)$. Apart from the parallel shift of the curves due to changes in initial conditions, it can be 


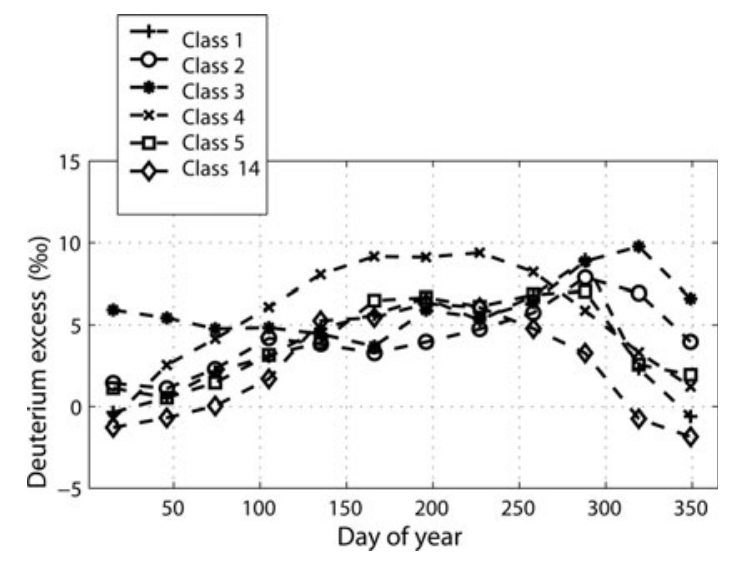

Fig. 3. Modelled mean annual cycle of deuterium excess for single trajectory classes.

seen that the model underestimates the annual amplitude of the data. This is due to several smoothing effects due to temporal (monthly values) and spatial averaging (moisture source area) of the source-area parameters. Additionally, the ERA40 data that were used for the closure equation solution underestimate daily and monthly temperature cycles (personal communication from A. Beljaars 2000). A further error source for source-area parameters is the error in the trajectory, which can be fairly large (see earlier) and of course leads to errors in the position of the source area. Whereas shifts in longitude do not have severe consequences, since most parameters of the polar oceans are fairly circumsymmetrical, a small error in latitude can lead to large errors in source-area parameters and thus in the results of the isotope modelling.

However, both model calculation and measurements show that whereas $\delta^{18} \mathrm{O}$ and $\mathrm{D}$ always have a maximum in the austral summer (December/March), the deuterium excess reaches its highest value already in spring (October).

\section{MODELLING OF ANNUAL COURSE OF DEUTERIUM EXCESS FOR EACH TRAJECTORY CLASS}

In Figure 3 the modelled annual course of deuterium excess for each trajectory class is shown. Whereas class 4 (lowlatitude origin) and class 14 (relatively low-latitude origin) show clear excess maxima in winter (July/August), the other classes do not reach maximum values before spring. In particular, class 3 (southern continental origin) shows a very prominent maximum in November. So for class 4 and class 14, the deuterium excess is in anti-phase with the $\delta^{18} \mathrm{O}$, similar to the findings mentioned earlier for lowaltitude sites in Greenland. Classes 4 and 14 together have a contribution of only $19 \%$ of all classes; however, the amounts of precipitation connected to these two classes are fairly high, since they are accompanied by advection of warm and thus moist air from comparatively low latitudes. Class 4 is of special interest for the EPICA deep drilling site Kohnen (EPICA-DML), since it can bring high amounts of precipitation even into the interior of the continent. This does not happen very often (four to five times per year), but can cause a high percentage of the yearly accumulation. Fifty percent of the annual accumulation results from only $12-25 \%$ of all precipitation events (Reijmer and Van den
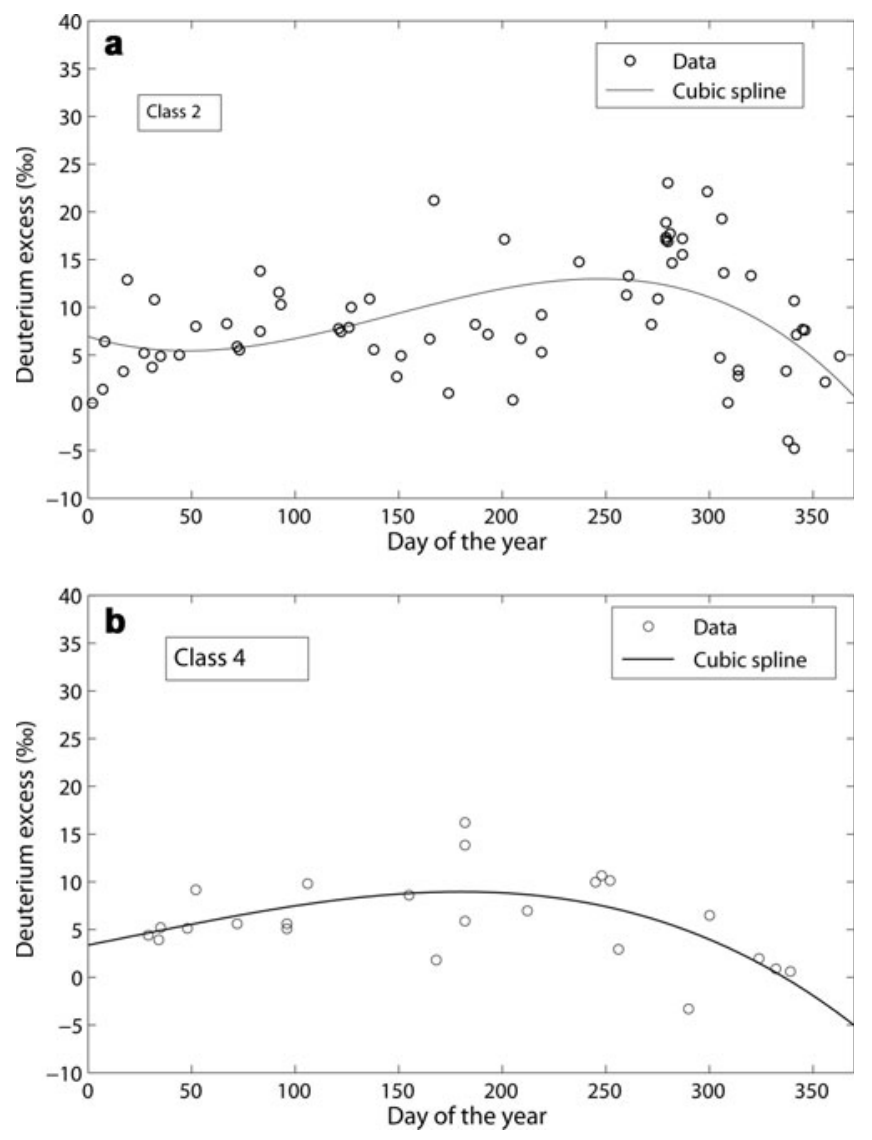

Fig. 4. Annual cycle of deuterium excess of surface snow samples at Neumayer station in the period 1981-2000: (a) for trajectory class 2, (b) for trajectory class 4 . For easier comparison with the model results, the data are shown together with cubic splines through the data points (see explanation in the text).

Broeke, 2003), the larger events usually meaning warm air advection from the north. Class 3 occurs in $13 \%$ of all cases and means moisture transport from the south, which corresponds to a long and complex precipitation and thus fractionation history. For this class the oceanic moisture source cannot be determined. Usually accumulation amounts for class 3 are not very high, but snowfall often occurs under weak wind conditions, thus the isotope data are very reliable, since no mixture with older snow occurs. In spite of the low accumulation amounts, the signal of this class can be very strong and must not be underestimated.

Figure 4 shows the deuterium excess of all surface snow samples corresponding to trajectory class 2 (Fig. 4a) with a spring maximum and of class 4 (Fig. $4 \mathrm{~b}$ ) with the maximum in winter. Again the cubic spline functions of the data are shown for better comparison with the modelled curve. Both data and model results show the same phase lag between the maxima of $\delta^{18} \mathrm{O}$ and deuterium excess. These curves cannot be shown for all classes because the number of measurements combined with the variability of the values is not always sufficient to calculate an unambiguous mean annual cycle.

\section{DISCUSSION}

What are the reasons for the phase lag between ${ }^{18} \mathrm{O}$ and deuterium excess? In an ice core there are different influences on this phase lag, one of these being post-depositional 
processes. As was shown by Schlosser and Oerter (2002), very effective diffusion processes occur within the snow cover during the first weeks to months after deposition. The initial annual amplitude of the seasonal cycle of $\delta^{18} \mathrm{O}$ measured in the fresh snow samples is reduced to about onethird, as was derived from comparison with firn cores. In the study presented here, we can exclude post-depositional processes, since the surface snow samples were taken immediately after the snowfall event. This enables us to investigate here the pure influence of precipitation origin and transport. It was shown that the two trajectory classes that are connected to advection of relatively warm, moist air from lower latitudes (classes 14 and 4) have an excess signal that is different from that of all other classes $(6.2 \%$ and $6.7 \%$, respectively). Simulations with a simple Rayleightype isotope model that was combined with a trajectory model confirm the results using data measured at the fresh snow samples.

\section{IMPLICATIONS FOR ICE-CORE INTERPRETATION}

The time lag between $\delta^{18} \mathrm{O}$ and deuterium excess found in an ice core can have many different explanations, including post-depositional processes and changes in the moisture source of precipitation. Strong excess signals from relatively few precipitation events can significantly influence the seasonal cycle of deuterium excess measured in Antarctic snow or ice. The term 'post-depositional processes' is a synonym for an at least partly 'black box', which contains: (i) the processes we do understand, like diffusion (e.g. Johnsen and Robin, 1983); (ii) the processes we do understand but cannot calculate quantitatively, like redistribution of snow by wind; and (iii) all processes we possibly do not know. These processes have to be studied in more detail to explain the different time lags between ${ }^{18} \mathrm{O}$ and deuterium excess $d$ in different geographical regions. In a core it is, of course, difficult to distinguish between the phase lag due to diffusion and that due to a change in moisture origin. One would assume that diffusion processes lead to a phase lag gradually changing with depth/age. However, a relatively sudden temporal change in the $\mathrm{d}-\delta^{18} \mathrm{O}$ phase difference in the annual course of these variables in a core should be taken as a hint to a change in the general atmospheric circulation. Systematic changes in the general atmospheric circulation mean changes in moisture sources and/or transport paths as well as changes in the seasonal distribution of accumulation. All these factors significantly influence the $\delta^{18} \mathrm{O}$-temperature relationship and can thus lead to strong biases and even artefacts in the stable-isotope profiles of ice cores.

\section{ACKNOWLEDGEMENTS}

We thank G. König-Langlo (AWI Bremerhaven) for providing the meteorological data and H.P. Scheele and the Royal Netherlands Meteorological Institute (KNMI) for the trajectory model. Thanks are due to all Neumayer winterers who carried out the fieldwork in Antarctica and to all people who were involved in the isotope analysis in the various labs, namely W. Graf (GSF, Neuherberg) and H. Meyer (AWI Potsdam). The GCM data were kindly provided by M. Werner, Jena. The glaciology group of Innsbruck University Network on Climate and Cryospheric Research (ICCR) is gratefully acknowledged for intensive discussion of the draft version. We also thank our reviewers, B. Vinther and two anonymous reviewers, as well as the scientific editor, R. Hock. The LSCE (Laboratoire des Sciences du Climat et de L'Environnement) ice-core group is funded by CEA (Commissariat à I'Energie Atomique), CNRS (Centre National de la Recherche Scientifique), Agence Nationale de la Recherche PICC (Paléoclimatigques: réduire les Incertitudes sur l'évolution du Climat des périodes Chaudes), and European Commission FP6 EPICA-MIS (marine isotopic stages) projects. This study receives financial support from the Austrian Science Fund (FWF; grant No. P15983-N06).

\section{REFERENCES}

Birnbaum, G. and R. Brauner. 2006. Synoptic situations causing high precipitation rates on the Antarctic plateau: observations from Kohnen Station, Dronning Maud Land. Antarct. Sci., 18(2), 279-288.

Ciais, P. and J. Jouzel. 1994. Deuterium and oxygen 18 in precipitation: isotopic model, including mixed cloud processes. J. Geophys. Res., 99(D8), 16,793-16,803.

Ciais, P., J.W.C. White, J. Jouzel and J.R. Petit. 1995. The origin of present-day Antarctic precipitation from surface snow deuterium excess data. J. Geophys. Res., 100(D9), 18,917-18,927.

Dansgaard, W. 1964. Stable isotopes in precipitation. Tellus, 16(4), 436-468.

Delaygue, G., V. Masson and J. Jouzel. 1999. Climatic stability of the geographic origin of Antarctic precipitation simulated by an atmospheric general circulation model. Ann. Glaciol., 29, 45-48.

Delaygue, G., V. Masson, J. Jouzel, R.D. Koster and R. Healy. 2000. The origin of Antarctic precipitation: a modelling approach. Tellus, 52B(1), 19-36.

Delmotte, M., V. Masson, J. Jouzel and V.I. Morgan. 2000. A seasonal deuterium excess signal at Law Dome, coastal eastern Antarctica: a Southern Ocean signature. J. Geophys. Res., 105(D6), 7187-7197.

EPICA Community Members. 2004. Eight glacial cycles from an Antarctic ice core. Nature, 429(6992), 623-628.

EPICA Community Members. 2006. One-to-one coupling of glacial climate variability in Greenland and Antarctica. Nature, 444(7116), 195-198.

Fisher, D.A. 1990. A zonally-averaged stable-isotope model coupled to a regional variable-elevation stable-isotope model. Ann. Glaciol., 14, 65-71.

Fujita, K. and O. Abe. 2006. Stable isotopes in daily precipitation at Dome Fuji, East Antarctica. Geophys. Res. Lett., 33(18), L18503. (10.1029/2006GL026936.)

Helsen, M.M. and 6 others. 2006. Modeling the isotopic composition of Antarctic snow using backward trajectories: simulation of snow pit records. J. Geophys. Res., 111(D15), D15109. (10.1029/2005JD006524.)

Hoffmann, G., M. Stiévenard, J. Jouzel, J.W.C. White and S.J. Johnsen. 1998a. Deuterium excess record from central Greenland: modelling and observations. In International Symposium on Isotope Techniques in the Study of Past and Current Environmental Changes in the Hydrosphere and the Atmosphere. Vienna, International Atomic Energy Agency, 591-602.

Hoffmann, G., M. Werner and M. Heimann. 1998b. Water isotope module of the ECHAM atmospheric general circulation model: a study on timescales from days to several years. J. Geophys. Res., 103(D14), 16,871-16,896.

Johnsen, S.J. and G.de Q. Robin. 1983. Diffusion of stable isotopes. In Robin, G.de Q., ed. The climatic record in polar ice sheets. Cambridge, etc., Cambridge University Press, 57-63.

Johnsen, S.J., W. Dansgaard and J.W.C. White. 1989. The origin of Arctic precipitation under present and glacial conditions. Tellus, 41B(4), 452-468. 
Jouzel, J. and L. Merlivat. 1984. Deuterium and oxygen 18 in precipitation: modeling of the isotopic effect during snow formation. J. Geophys. Res., 89(D7), 11,749-11,757.

Jouzel, J. and 12 others. 1997. Validity of the temperature reconstruction from water isotopes in ice cores. J. Geophys. Res., 102(C12), 26,471-26,487.

Jouzel, J. and 6 others. 2003. Magnitude of isotope/temperature scaling for interpretation of central Antarctic ice cores. J. Geophys. Res., 108(D12), 4361-4370.

Kahl, J.D., J.M. Harris and G.A. Herbert. 1989. Intercomparison of three long-range trajectory models applied to Arctic haze. Tellus, 41B(4), 524-536.

Kottmeyer, C. and B. Fay. 1998. Trajectories in the Antarctic lower troposphere. J. Geophys. Res., 103(D9), 10,947-10,959.

König-Langlo, G. and B. Marx. 1997. The meteorological information system at the Alfred-Wegener Institute. In Lautenschlager, M. and M. Reinke, eds. Climate and environmental database systems. Dordrecht, etc., Kluwer Academic Publishers, 117-125.

Mason, B.J. 1971. The physics of clouds. Second edition. Oxford, etc., Clarendon Press.

Masson-Delmotte, V. and 6 others. 2003. Recent southern Indian Ocean climate variability inferred from a Law Dome ice core. Climate Dyn., 21(2), 153-166.

Merlivat, L. and J. Jouzel. 1979. Global climatic interpretation of the deuterium-oxygen 18 relationship for precipitation. J. Geophys. Res., 84(C8), 5029-5033.

Noone, D. and I. Simmonds. 1998. Implications for the interpretation of ice-core isotope data from analysis of modelled Antarctic precipitation. Ann. Glaciol., 27, 398-402.

Noone, D., J. Turner and R. Mulvaney. 1999. Atmospheric signals and characteristics of accumulation in Dronning Maud Land, Antarctica. J. Geophys. Res., 104(D16), 19,191-19,211.

North Greenland Icecore Project (NorthGRIP) Members. 2004. High-resolution record of Northern Hemisphere climate extending into the last interglacial period. Nature, 431(7005), 147-151.

Oerter, H., W. Graf, H. Meyer and F. Wilhelms. 2004. The EPICA ice core from Dronning Maud Land: first results from stableisotope measurements. Ann. Glaciol., 39, 307-312.

Parrenin, F. and 15 others. 2007. Ice flow modelling at EPICA Dome C and Dome Fuji, East Antarctica. Clim. Past Discuss., 3(1), 19-61.
Pfaff, K.-H. 1993. ${ }^{2} \mathrm{H}$ und ${ }^{18} \mathrm{O}-$ Gehalte in den Niederschlägen in Abhängigkeit von der meteorologischen Situation im Bereich der Georg-von-Neumayer-Station, Antarktis. (PhD thesis, University of Innsbruck.)

Reijmer, C.H. and M.R. van den Broeke. 2001. Moisture sources of precipitation in western Dronning Maud Land, Antarctica. Antarct. Sci., 13(2), 210-220.

Reijmer, C.H. and M.R. van den Broeke. 2003. Temporal and spatial variability of the surface mass balance in Dronning Maud Land, Antarctica, as derived from automatic weather stations. J. Glaciol., 49(167), 512-520.

Reijmer, C.H., M.R. van den Broeke and M.P. Scheele. 2002. Air parcel trajectories and snowfall related to five deep drilling locations on Antarctica based on the ERA-15 dataset. J. Climate, 15(14), 1957-1968.

Scheele, M.P., P.C. Sigmund and P.F.J. van Velthoven. 1996 Sensitivity of trajectories to data resolution and its dependence on the starting point: in or outside a tropopause fold. Meteorol. Appl., 3, 267-273.

Schlosser, E. 1999. Effects of seasonal variability of accumulation on yearly mean $\delta^{18} \mathrm{O}$ values in Antarctic snow. J. Glaciol., 45(151), 463-468.

Schlosser, E. and H. Oerter. 2002. Seasonal variations of accumulation and the isotope record in ice cores: a study with surface snow samples and firn cores from Neumayer station, Antarctica. Ann. Glaciol., 35, 97-101.

Schlosser, E., C. Reijmer, H. Oerter and W. Graf. 2004. The influence of precipitation origin on the $\delta^{18} \mathrm{O}-T$ relationship at Neumayer station, Ekströmisen, Antarctica. Ann. Glaciol., 39, 41-48.

Steig, E.J., P.M. Grootes and M. Stuiver. 1994. Seasonal precipitation timing and ice core records. Science, 266(5192), 1885-1886.

Stohl, A., G. Wotawa, P. Seibert and H. Kromp-Kolb. 1995. Interpolation errors in wind fields as a function of spatial and temporal resolution and their impact on different types of kinematic trajectories. J. Appl. Meteorol., 34(10), 2149-2165.

Stohl, A., L. Heimberger, M.P. Scheele and H. Wernli. 2001. An intercomparison of results from three trajectory models. Meteorol. Appl., 8, 127-135.

Werner, M., U. Mikolajewicz, M. Heimann and G. Hoffmann. 2000. Borehole versus isotope temperatures on Greenland: seasonality does matter. Geophys. Res. Lett., 27(5), 723-726.

MS received 13 March 2007 and accepted in revised form 8 October 2007 